\title{
DNA Polymerase Alpha
}

National Cancer Institute

\section{Source}

National Cancer Institute. DNA Polymerase Alpha. NCI Thesaurus. Code C16510.

An enzyme that plays major roles in DNA metabolism. The protein, which exhibits bidirectional nuclease activity is required for both DNA synthesis and repair. DNA polymerase alpha is most active in dividing cells, and is primarily involved with lagging strand synthesis. 